Received: 2016.04.11 Accepted: 2016.06.14 Published: 2016.11 .08

\title{
Impact of Postoperative Bleeding on Short-Term Outcome in Patients After Orthotopic Heart Transplantation: A Retrospective Cohort Study
}

Authors' Contribution: Study Design A Data Collection B Statistical Analysis C Data Interpretation D Manuscript Preparation E Literature Search F Funds Collection G
ABCDEF 1 Anna Kędziora

ACDEFG 2,3 Karol Wierzbicki

DEF 2,3 Piotr Mazur

DEF 1 Bryan HyoChan Song

ACDE 2,3 Jacek Piątek

DE 2,3 Irena Milaniak

DE 2,3 Piotr Węgrzyn

DEG 2,3 Bogusław Kapelak

DE 2,3 Rafał Drwiła

DE 2,3 Dorota Sobczyk

DE 2,3 Izabela Górkiewicz-Kot

DE 2,3 Krzysztof Bartuś

DE 2,3 Bogdan Niekowal

DEG 2,3 Jerzy Sadowski
1 Cardiosurgical Students' Scientific Group, Jagiellonian University Medical College, Cracow, Poland

2 Institute of Cardiology, Jagiellonian University Medical College, Cracow, Poland 3 Department of Cardiovascular Surgery and Transplantology, John Paul II Hospital, Cracow, Poland
Corresponding Authors: Source of support:
Karol Wierzbicki, e-mail: lolekwierzbicki@onet.pl, Anna Kędziora, e-mail: anna.kedziora.mail@gmail.com

This study was funded by a grant from the Jagiellonian University Medical College (No. K/ZDS/004595, to KW)

Background: Orthotopic heart transplantation (HTX) remains the ultimate treatment option in patients with end-stage heart failure, endorsed by the European Society of Cardiology guidelines. The aim of the study is a complex evaluation of the postoperative bleeding after HTX and its influence on short-term outcome.

Material/Methods: A retrospective cohort study consisted of 53 patients (4 females and 49 males, median age 52.5 years, IQR 17 years) who underwent HTX in the Department of Cardiovascular Surgery and Transplantology of John Paul II Hospital in Krakow between 2007 and 2014.

Results: The median chest tube output within first 24 hours after the surgery was 695 (550-870) mL. Bleeding decreased throughout the observation $(p=0.000)$. The first postoperative hemoglobin level was a significant predictor of excessive blood loss $(p=0.017)$. The volume of chest tube output increased the duration of mechanical ventilation $(p=0.046)$ and the incidence of re-exploration after first 24 hours of observation $(p=0.049)$. In patients with higher chest tube output, more packed red blood cells (PRBC), fresh frozen plasma (FFP), and platelet (PLT) transfusions were required $(p=0.000, p=0.019$, and $p=0.000$, respectively). Early rethoracotomy (within the first 24 hours post-surgery) increased the in-hospital mortality ( $p=0.021$; OR 7.43 [1.36-40.64]).

Conclusions: The study demonstrates the importance of postoperative bleeding and bleeding complications for short-term outcome in our post-HTX cohort. Throughout the analysis, the first postoperative hemoglobin level was detected to be a significant predictor of postoperative blood loss.

MeSH Keywords: Chest Tubes • Erythrocyte Transfusion • Heart Transplantation • Postoperative Hemorrhage • Treatment Outcome

Full-text PDF: http://www.annalsoftransplantation.com/abstract/index/idArt/898988

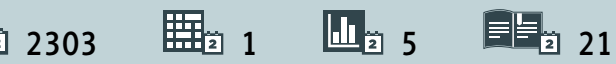




\section{Background}

Orthotopic heart transplantation (HTX) is a recommended treatment option for selected patients with end-stage heart failure. According to the European Society of Cardiology (ESC) guidelines, it remains the gold-standard treatment, and improves survival, stamina, and quality of life [1]. Nevertheless, transplant surgery faces increasing difficulty as the waiting time becomes prolonged due to the donor shortage. As a result, most of the patients who qualify for HTX are now almost entirely urgent cases $[2,3]$. Patients in such a deteriorated state suffer from greater incidences of major complications, including postoperative bleeding. Moreover, the necessity to accept extended criteria donors results in further complications postoperatively. Analysis of risk factors for poor outcome is crucial to ensure gold-standard perioperative management.

Bleeding and consequent blood product transfusions are common in patients operated on with cardiopulmonary bypass (CPB), and occur more frequently after HTX than after other cardiac procedures. They are associated with an increased risk of major complications and early mortality, even when the patient does not require rethoracotomy $[4,5]$. Along with primary graft failure and arrhythmias, they are the most commonly observed complications during the early postoperative period [6]. Currently, there are only limited scientific data provided by case studies that describe the short-term outcomes of postoperative bleeding and its defining factors. This paper aimed to fill this gap in knowledge.

The objective of the study is a complex evaluation of the postoperative bleeding after HTX and its influence on short-term outcome.

\section{Material and Methods}

In a retrospective cohort study we analyzed 55 consecutive patients who underwent HTX between January 2007 and August 2014 in the Department of Cardiovascular Surgery and Transplantology of the John Paul II Hospital in Cracow. Postoperative chest tube output was assessed throughout the first 24 hours after the surgery. Only patients with complete postoperative drainage data were included in the study. One patient was excluded from analysis due to death within first 24 hours that was not caused by excessive hemorrhage and another due to inaccessibility of complete postoperative drainage data.

The final analysis consisted of 53 patients. The majority were men $(92.5 \%)$ with a median age of 52.5 years who were suffering from dilated cardiomyopathy (75.5\%) and had normal body mass index (BMI) (median BMI $24.9 \mathrm{~kg} / \mathrm{m}^{2}$ ). A minority
Table 1. Baseline characteristics of HTX patients $(n=53)$.

\begin{tabular}{|lcc}
\hline \multicolumn{1}{c}{ Variable } & \multicolumn{2}{c}{ Value } \\
\hline Age, years & 52.5 & $(40.0-57.0)$ \\
\hline Male sex, $\mathrm{n}(\%)$ & 49 & $(92.5)$ \\
\hline BMl, kg/m² & 24.9 & $(22.4-28.7)$ \\
\hline Ischemic cardiomyopathy, $\mathrm{n}(\%)$ & 13 & $(24.5)$ \\
\hline Dilated cardiomyopathy, $\mathrm{n}(\%)$ & 40 & $(75.5)$ \\
\hline Coronary artery disease, $\mathrm{n}$ (\%) & 18 & $(34)$ \\
\hline Diabetes mellitus, $\mathrm{n}(\%)$ & 11 & $(20.8)$ \\
\hline Arterial hypertension, $\mathrm{n}(\%)$ & 21 & $(39.6)$ \\
\hline Hypercholesterolemia, $\mathrm{n}(\%)$ & 16 & $(30.2)$ \\
\hline Atrial fibrillation, $\mathrm{n}(\%)$ & 10 & $(18.9)$ \\
\hline Previous cardiac surgery, $\mathrm{n}(\%)$ & 25 & $(47.2)$ \\
\hline Previous PCl, $\mathrm{n}(\%)$ & 7 & $(13.2)$ \\
\hline Medication & & \\
\hline Aspirin, $\mathrm{n}(\%)$ & 14 & $(26.4)$ \\
\hline Clopidogrel, $\mathrm{n}(\%)$ & 2 & $(3.8)$ \\
\hline Warfarin, $\mathrm{n}$ (\%) & 6 & $(11.3)$ \\
\hline
\end{tabular}

Data are shown as mean \pm SD or as median (IQR), or number (percentage). $\mathrm{BMI}$ - body mass index; $\mathrm{PCl}$ - percutaneous coronary intervention.

of the patients required previous antiplatelet or anticoagulant therapy (26.4\% aspirin, 3.8\% clopidogrel, and $11.3 \%$ warfarin) (Table 1).

In all patients, HTX was performed using the biatrial method. All patients were operated on in hypothermia of $28^{\circ} \mathrm{C}$ using CPB. General anesthesia was effectuated via propofol as hypnotic, sufentanil as analgesic, and non-depolarizing muscle relaxant. Full heparinization was achieved before starting CPB and was subsequently reversed with protamine. The standard protocol includes heparin $3 \mathrm{mg} / \mathrm{kg}$ and protamine 1:1. All harvested hearts were protected with crystalloid cardioplegia (Celsior ${ }^{\circledR}$ ), as previously described [7]. The median procedure time, extracorporeal circulation (ECC) time, total ischemic time (TIT), and reperfusion time were 300 (240-360), 212.5 (187-246), 148 (125-190), and 63 (45-82) minutes, respectively.

Postoperatively, all patients received immunosuppressive treatment with calcineurin inhibitor, mycophenolate mofetil, and corticosteroids. In addition, anti-thymocyte globulin was administered during induction of immunosuppression (dosage of anti-thymocyte globulin was determined on the basis of CD3 lymphocyte count) [8]. All patients required inotropic support with median use of 2 (2-3) inotropic drugs (epinephrine, norepinephrine, dobutamine, milrinone). The treatment 


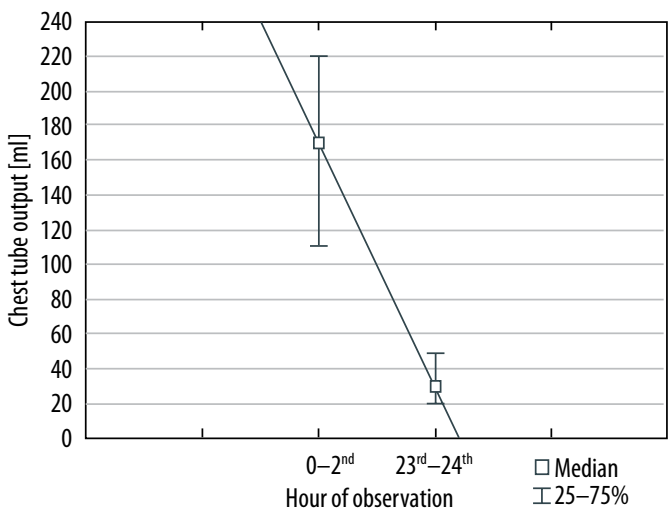

Figure 1. Chest tube output from the first two hours of observation $\left(0-2^{\text {nd }}\right)$ against chest tube output from the last two hours of observation $\left(23^{\text {rd }}-24^{\text {th }}\right)$. Wilcoxon signed-rank test $p=0.000$.

was based on hemodynamic measurements achieved with the Swan-Ganz catheter.

Bleeding complications were described by a few parameters (drainage volume, need for rethoracotomy, blood products transfusions), because only then could the whole spectrum of this complication be discussed. Chest tube drainage, hemoglobin level, and requirement for packed red blood cells (PRBC), fresh frozen plasma (FFP), and platelet (PLT) transfusion were recorded every two hours during first 24 hours post-surgery.

Duration of mechanical ventilation and duration of intensive care unit (ICU) stay were evaluated for patients who were discharged from ICU. Death before discharge, need for early (within the first 24 hours post-surgery) and late (after the first 24 hours post-surgery) rethoracotomy, and prolonged mechanical ventilation (more than 72 hours) were assessed for all patients.

Parameters describing postoperative bleeding were tested for association with short-term outcome, evaluated by duration of mechanical ventilation and ICU stay, prolonged mechanical ventilation, and death before discharge.

\section{Statistical analysis}

STATISTICA 8.0 (StatSoft $^{\circledR}$ ) was used for statistical analysis. In order to confirm a normal distribution of continuous variables, the Shapiro-Wilk test was used. Results are presented based on the parameters of descriptive statistics, including mean values and their standard deviations or median values and quartiles, as appropriate. Categorical variables are presented as percentages. Non-parametric tests were used for further analysis due to the non-normal distribution of continuous variables. The Wilcoxon signed-rank test was used

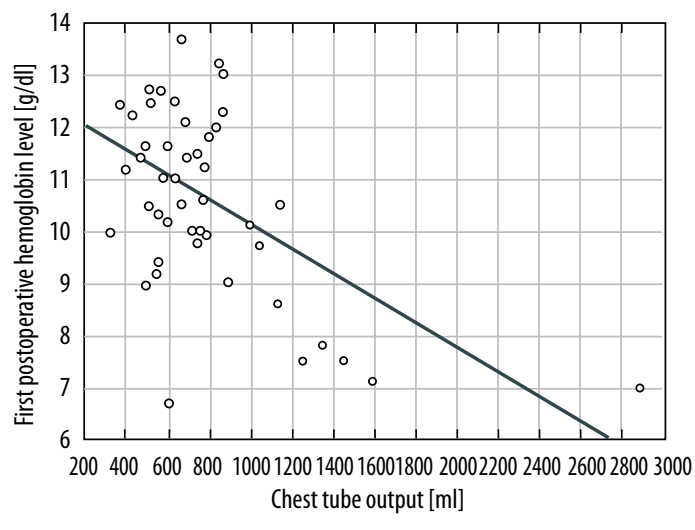

Figure 2. First postoperative hemoglobin level against 24-hour chest tube output. Spearman's rho test $p=0.017$.

to compare repeated measurements on a single sample. The Mann-Whitney $U$ test was used to examine the differences between two independent groups. Spearman's rank correlation coefficient (Spearman's rho) was used to assess linear correlation between variables. Univariate logistic regression was used to test the influence of postoperative bleeding and bleeding complications on short-term outcome. A $P$ value less than 0.05 was considered significant.

\section{Results}

The median chest tube output within first 24 hours after the surgery was estimated at the level of 695 (550-870) mL. Bleeding decreased throughout the observation. Median drainage volume within first two hours of observation was 170 (110220) $\mathrm{mL}$ and was $30(20-50) \mathrm{mL}$ within the last two hours $(p=0.000)$ (Figure 1). The first postoperative hemoglobin level was detected to be a significant predictor of excessive blood loss ( $p=0.017$ ) (Figure 2).

Throughout the observation, 34 patients (64.2\%) required PRBC, 19 (35.9\%) FFP, and 13 (24.5\%) PLT transfusions. The median number of units used for each patient stood at $3(2-5)$ for PRBC, 4 (3-4) for FFP, and 1 (1-1) for PLT.

The median mechanical ventilation time was 2 (1-7) days. Prolonged mechanical ventilation (more than 72 hours) was observed in 17 cases (32.1\%). The median duration of ICU stay and the postoperative hospitalization was 9 (6-17) and 36 (32-42) days. Death before discharge occurred in 11 cases $(20.1 \%)$.

Seven patients (13.2\%) required early rethoracotomy (within first 24 hours post-surgery). The median time between the HTX and re-exploration was 7 (6-15) hours. Late rethoracotomy 


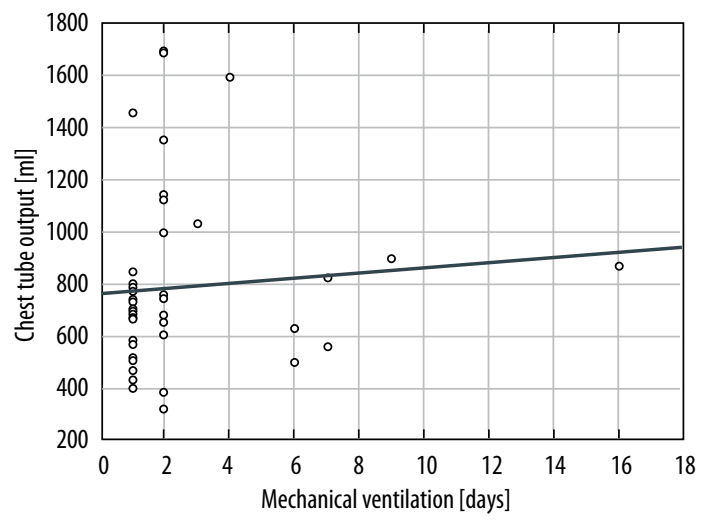

Figure 3. Twenty-four hour post-surgery chest tube output against duration of mechanical ventilation. Spearman's rho test $p=0.046$.

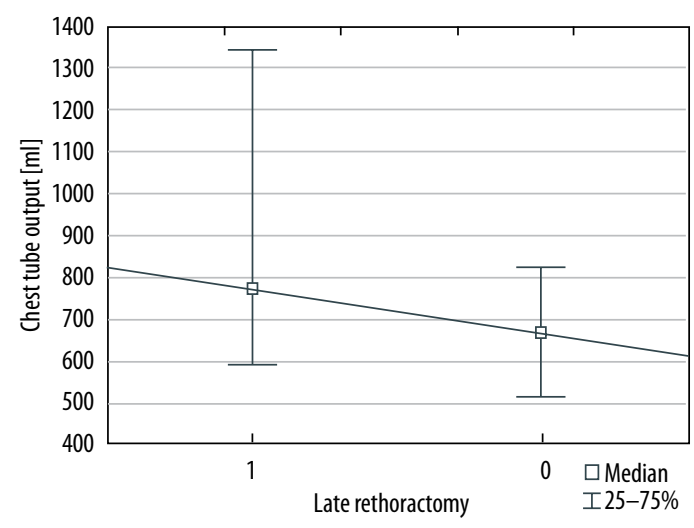

Figure 4. Twenty-four hour chest tube output against requirement for late rethoracotomy. Mann-Whitney $U$ test $p=0.048$.

(after first 24 hours post-surgery) was necessary in 20 cases (37.7\%), and 7 patients (13.2\%) needed re-exploration more than once.

The volume of chest tube drainage was associated with duration of mechanical ventilation $(p=0.046)$ (Figure 3$)$. The volume of chest tube drainage did not influence the duration of ICU stay, incidence of prolonged mechanical ventilation, and in-hospital mortality ( $p>0.05$ for all).

The volume of chest tube drainage influenced the necessity of late rethoracotomy (median of 775 [595-1350] mL vs. 670 [520$830] \mathrm{mL} ; \mathrm{p}=0.049$ ) (Figure 4), but higher volumes were not observed in patients who required early rethoracotomy ( $p>0.05)$.

The need for early rethoracotomy was not associated with duration of mechanical ventilation and ICU stay, and prolonged

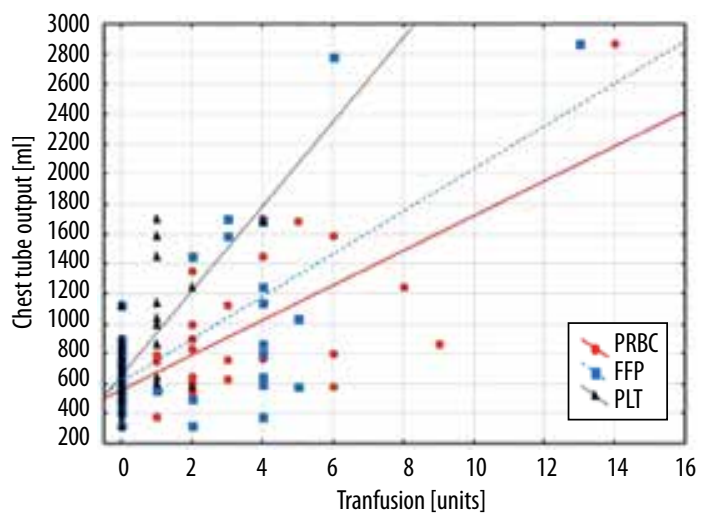

Figure 5. Chest tube output against requirement for blood product transfusions within first 24 hours post-surgery. Spearman's rho test PRBC $p=0.000 ;$ FFP $p=0.019 ; \mathrm{PLT}$ $p=0.000$.

mechanical ventilation ( $p>0.05$ for all). However, it significantly increased the in-hospital mortality $(p=0.021$; OR 7.43 [1.36-40.64]).

Late rethoracotomy was not associated with duration of mechanical ventilation and ICU stay in patients who were discharged from the ICU ( $p>0.05$ for all). It increased the incidence of prolonged mechanical ventilation ( $p=0.007$; OR 5.5 [1.5819.17]), but did not increase the risk of in-hospital mortality.

In patients with higher chest tube output, more PRBC, FFP, and PLT transfusions were required $(p=0.000 ; p=0.019$, and $p=0.000$, respectively) (Figure 5).

The amount of PRBC transfused to HTX recipients was found to increase the duration of mechanical ventilation and ICU stay $(p=0.000$ and $p=0.001$, respectively). The number of PRBC units influenced also the incidence of prolonged mechanical ventilation and in-hospital mortality $(p=0.008$; OR 1.43 [1.10-1.88] and $p=0.036$; OR 1.30 [1.02-1.65], respectively, for every unit transfused). Notably, this defining factor of PRBC transfusions was also associated with the drainage volume, and it had an impact on the outcome similar to that of the drainage volume.

FFP and PLT transfusions were not associated with short-term outcome (duration of mechanical ventilation and ICU stay, prolonged mechanical ventilation, death before discharge; p>0.05 for all).

\section{Discussion}

In recent years, an increasing number of cardiac transplantations have been observed worldwide. The survival following 
this procedure has increased since the technique was first developed, and the International Registry for Heart and Lung Transplantation (ISHLT) shows a half-life time of more than 10 years [9]. Nevertheless, the early postoperative period is still associated with the highest mortality rates. It is suspected that majority of the mortalities are due to the high-risk profiles of the recipients, as well as primary graft failures [10].

Apart from primary graft failure, studies present arrhythmia and postoperative bleeding as the most common complications in this group of patients [6]. Many studies underline increased risk of poor outcome after cardiac procedures in association with postoperative bleeding $[4,5,11,12]$. The risk of bleeding complications is present even in the case of elective procedures, where there is at least a potential possibility of undertaking preventive measures. Emergent cardiac procedures are associated with an elevated risk of early mortality and major complications [10]. Heart transplantations face this issue as all of them are performed urgently. Moreover, atrial fibrillation and previous valve surgeries may require continuous anticoagulation treatment. The data on perioperative discontinuation of therapy were inconclusive [13]. In addition, the prevalence of spontaneously occurring coagulopathy in patients with end-stage heart failure (qualified for HTX) has increased within recent years and results in a higher risk of in-hospital mortality [14]. This study is the first to describe the impact of postoperative bleeding and bleeding complications on shortterm outcome in patients after HTX.

In our study group, high postoperative bleeding correlated with mechanical ventilation time, as has been observed after other cardiac procedures $[4,11]$. This complication usually increases the risk of infection, negatively influences postoperative pulmonary rehabilitation, and is combined with increased mortality [15]. Similar to drainage volume, the amount of PRBC transfused increased the duration of mechanical ventilation in analyzed HTX recipients. Although blood product transfusion following HTX is regulated by a strict protocol (such as leukocyte filters and irradiation), the risk of transfusion-related acute lung injury (TRALI) is not completely abolished and a higher incidence of this complication is observed among transplant recipients [16].

Moreover, postoperative bleeding may also exacerbate primary graft failure (PGF), which is considered to be the cause of 30 -day death in $36 \%$ of patients after HTX. Blood loss contributes to hypovolemic shock, which worsens the outcome of patients whose blood pressure and organ perfusion are already low due to cardiogenic shock associated with PGF $[17,18]$.

Therefore, the overall mortality in patients after cardiac procedures is often higher in groups who have excessive postoperative bleeding and who require blood product transfusions.
In the study by Diaz-Martin et al., the patients who received more than 6 units of blood were found to have significantly higher ICU mortality (33.3\% vs. 4\%; $p=0.01$ ) [18]. Similar observations were found in our study cohort of HTX recipients. The amount of PRBC transfused increased the in-hospital mortality.

Re-exploration for bleeding is commonly considered to be an independent risk factor for prolonged hospitalization and mortality in cardiac surgery [19]. In our study group, rethoracotomy was associated with the risk of death before discharge and duration of ICU stay. The rate of early rethoracotomies was high, despite the fact that overall chest tube drainage volumes were similar to those in elective cardiac surgeries in our institution [20]. This suggests that clinical criteria and hemodynamic parameters are more important in consideration for early rethoracotomy in HTX recipients than the volume of blood loss. Late rethoracotomies were performed more frequently when chest tube output from first 24 hours after the surgery was high.

There have been previous attempts to develop a predictive model to identify patients who may present with severe bleeding after cardiac surgery. Nevertheless, various articles present different risk factors that could contribute to excessive bleeding. The Papworth Bleeding Risk Score (BriSC) is a stratification system based on more than 6000 patients and has a high negative predictive value [21]. However, the positive predictive value of the presented BriSC is low, as only $21 \%$ of the patients who were rated as high risk did in fact bleed severely. Nevertheless, all HTX recipients are placed at least in the median-risk group with $8 \%$ prevalence of bleeding complications. According to BriSC, this is due to procedure priority and the complexion of the surgery in comparison to an isolated CABG or a single valve surgery. Therefore, excessive bleeding should be expected in HTX recipients and, as our study demonstrates, should be considered a major complication that may worsen the short-term outcome.

Despite the original study aim of assessing the impact of postoperative bleeding and bleeding complications on the shortterm outcome, the first postoperative hemoglobin level was detected as the significant predictor of excessive blood loss. It correlated with the chest tube output volume, the amount of PRBC used, and the need for rethoracotomy within first 24 hours. This may suggest that HTX recipients with low postoperative hemoglobin values should be considered at risk.

Further study is warranted to develop gold-standard management to lower the incidence of postoperative bleeding and its complications, such as the need for blood product transfusions and rethoracotomy. 


\section{Conclusions}

The study demonstrates the importance of postoperative bleeding and bleeding complications for short-term outcome in our post-HTX cohort. The volume of chest tube drainage, PRBC transfusions, and need for rethoracotomy had an impact on the most important factors in the postoperative course, including death before discharge, prolonged mechanical ventilation, and duration of ICU stay. Although the study was not

\section{References:}

1. Task Force Members: ESC Guidelines for the diagnosis and treatment of acute and chronic heart failure 2012: The Task Force for the Diagnosis and Treatment of Acute and Chronic Heart Failure 2012 of the European Society of Cardiology. Developed in collaboration with the Heart Failure Association (HFA) of the ESC. Eur Heart J, 2012; 33: 1787-47

2. Smits JM: Actual situation in Eurotransplant regarding high urgent heart transplantation. Eur J Cardiothorac Surg, 2012; 42: 609-11

3. Stehlik J, Stevenson LW, Edwards LB et al: Organ allocation around the world: Insights from the ISHLT international registry for heart and lung transplantation. J Heart Lung Transplant, 2014; 33: 975-84

4. Garcia-Villarreal OA: Postoperative bleeding in cardiac surgery: The issue is not resolved yet. Interact CardioVasc Thorac Surg, 2012; 14: 713

5. Christensen MC, Dziewior F, Kempel A et al: Increased chest tube drainage is independently associated with adverse outcome after cardiac surgery. J Cardiothorac Vasc Anesth, 2012; 26: 46-51

6. Kim HJ, Jung S-H, Kim JJ et al: Early postoperative complications after heart transplantation in adult recipients: Asan Medical Center Experience. Korean J Thorac Cardiovasc Surg, 2013; 46: 426-32

7. Wierzbicki K, Sobczyk D, Milaniak I et al: Assessment of the influence of elevated troponin I levels measured in the perioperative period on the clinical course of patients after heart transplantation in own material. Kardiochirurgia i Torakochirurgia Polska, 2011; 8: 379-82

8. Zalecenia dotyczące leczenia immunosupresyjnego po przeszczepieniu narządów unaczynionych opracowane przez Polskie Towarzystwo Transplantacyjne, Konsultanta Krajowego w dziedzinie Transplantologi Klinicznej. Warszawa, 2012 [in Polish]

9. Lund LH, Edwards LB, Kucheryavaya AY et al: The Registry of the International Society for Heart and Lung Transplantation: Thirty-first Official Adult Heart Transplant Report - 2014; Focus Theme: Retransplantation. J Heart Lung Transplant, 2014; 33: 996-1008

10. Ding W, Ji Q, Shi Y, Ma R: Predictors of low cardiac output syndrome after isolated coronary artery bypass grafting. Int Heart J, 2015; 56: 144-49 designed to evaluate predictors or risk factors for excessive bleeding, throughout the analysis the first postoperative hemoglobin level was detected to be a significant predictor of postoperative blood loss.

\section{Conflict of interest}

The authors report no conflict of interest.

11. Mehta R, Sheng S, O'Brien SM et al: reoperation for bleeding in patients undergoing coronary artery bypass surgery. incidence, risk factors, time trends, and outcomes. Circulation, 2009; 2: 583-90

12. Kinduris S, Vaisvila T, Petronyte J et al: Bleeding after cardiac surgery: Risk factors, frequency, and outcomes. Medicina (Kaunas), 2006; 42: 566-70

13. Oh CS, Choi JW, Jung E et al: Warfarin therapy and perioperative transfusion requirement with bleeding amount in patients undergoing cardiac surgery with cardiopulmonary bypass: A retrospective study. Transfus Med, 2015; 25: 33-37

14. Mujib M, Khanna N, Mazumder NK et al: Pretransplant coagulopathy and in-hospital outcomes among heart transplant recipients: A propensitymatched nationwide inpatient sample study. Clin Cardiol, 2015; 38: 300-8

15. Chen C, Zhang Z, Chen T et al: Prolonged mechanical ventilation-induced neuroinflammation affects postoperative memory dysfunction in surgical mice. Crit Care, 2015; 19: 159

16. Clifford L, Jia Q, Subramanian A et al: Characterizing the epidemiology of postoperative transfusion-related acute lung injury. Anesthesiology, 2015 122: $12-20$

17. Wierzbicki K, Bochenek M, Kędziora A et al: Does the postoperative troponin I blood concentration measured in the perioperative period influence hemodynamic function of a transplanted heart? Kardiochirurgia i Torakochirurgia Polska, 2014; 11: 289-93

18. Diaz-Martin A, Escoresca-Ortega AM, Hernandez-Caballero $C$ et al: Considerations regarding major bleeding after cardiac transplantation. Transplant Proc, 2010; 42: 3204-5

19. Kristensen KL, Rauer LJ, Mortensen PE et al: Reoperation for bleeding in cardiac surgery. Interact CardioVasc Thorac Surg, 2012; 14: 709-13

20. Mazur P, Plicner D, Zdziarska J et al: Decreased von Willebrand factor ristocetin cofactor activity and increased ADAMTS13 antigen increase postoperative drainage after coronary artery bypass grafting. Eur J Cardiothorac Surg, 2014; 45: e26-32

21. Vuylsteke A, Pagel C, Gerrard C et al: The Papworth Bleeding Risk Score: A stratification scheme for identifying cardiac surgery patients at risk of excessive early postoperative bleeding. Eur J Cardiothorac Surg, 2011; 39: 924-30 